Departamento de Doenças Infectuosas e Parasitárias Diretor: Prof. Dr. Laerte Machado Guimarães

\title{
MICOSE EM BOVINOS DE SÃO PAULO POR "TRICOPHYTON FAVIFORME ALBUM" (SABOURAUD, 1909) $\left(^{*}\right)$
}

\section{Laerte Machado Guimarães e Paulo M. G. Lacerda Jr.}

2 estampas (5 figuras)

\author{
Assistente
}

Em junho de 1944 observamos lesões semelhantes às das tinhas em 9 bezerros, na Faculdade de Medicina Veterinária, cujo estudo constitui motivo desta publicação.

Os animais eram procedentes de Angatuba e Santo Amaro; foram mantidos junto a equinos e a outros bovinos jovens e adultos. Lesões cutâneas com queda de pêlo foram observadas em um deles e logo a seguir os 8 restantes mostraram-se afetados, o que não aconteceu com os outros animais (bovinos e equinos) com os quais mantivera contacto.

LOCALIZAÇÃO E ASPECTO DAS LESÕES - As lesões instalavam-se com mais freqüência na cabeça e pescoço, e raramente em outras regiões tais como: dorso, ventre e coxas.

Inicialmente percebiam-se lesões de 1 centímetro no seu maior diâmetro, arredondadas, com queda de pêlo caminhando do centro para a periferia, secas e escamosas, de coloração esbranquiçada. Aumentavam progressivamente atingindo até cerca de 5 centímetros de diâmetro (Fig. 1). Outras vezes havia confluência com acentuada queratinização lembrando ligeiramente o aspecto do papiloma verrucoso (Fig. 2).

Retiramos escamas e pêlos para exame microscópico e semeadura cujos resultados passamos a descrever:

O PARASITO NO PÊLO - Já macroscòpicamente podia-se prever o parasitismo: entre os muitos pêlos retirados das lesões pela raspagem e misturados com escamas, podiam-se reconhecer que alguns estavam partidos e envolvidos até certa altura, por uma bainha de côr esbranquiçada.

Tratados quer pela solução de potassa a $30 \%$, quer pelo método de BerLese (goma e cloral), mostraram-se parasitados por um tri-

(*) Agradecemos ao Prof. Dr. Abílio Martins de Cr tro a orientação recebída como também sua colaboraçấo direta quer na confirmação do diagnóstico por nós estabelecido, quer no estudo das culturas. 
cófito do grupo dos ectótrices megalosporos de que, segundo SARABOUD, conhecem-se bem sete espécies: 4 de culturas penugentas ( $T$. rosaceum, $T$. vinosum, T. album e T. discoides), e 3 de culturas faviformes ( $T$. ochraceum, T. album e T. discoides) estas últimas de origem animal e sobretudo bovina ou equina. A infestação dos pêlos era grande e reconheciam-se muito bem filamentos esporulados de sede intrapilar e de sede peripilar. Os filamentos micelianos intrapilares eram em menor número e de aspecto polimorfo, vendo-se alguns, cujos artículos pequenos e quadrangulares seriavam-se em rosário e com poucos elementos, donde resultava serem curtos, dispostos paralela ou oblíquamente em relação ao maior eixo do pêlo; em certos pontos e geralmente nos mais próximos da raiz, dispunham-se os artículos não em filamentos, mas sob forma de mosáico, com poucos elementos. Eram, pensamos, artículos de filamentos desagregados. Alem dêsses elementos em rosário e em mosáico, viam-se poucos filamentos muito longos e feitos de artículos tambem longos. Pareceram-nos imaturos, elementos de invasão do pêlo.

Igualmente nítido era o aglomerado de esporos, constituindo bainha peripilar, esporos todos monomorfos: organizavam-se em rosário, eram tão mais visíveis nessa disposição quanto mais próximos do pêlo; os artículos eram grandes e de forma redonda, ou arrendondada e facetada, onde mais abundantes e, por isso, mais comprimidos uns de encontro aos outros. (Fig. 3 e 4).

Não foi possível obter culturas puras com material - pêlos e escamas da lesão animal; em mais de duas dezenas de tubos semeados só se desenvolveram culturas de aspergilos e de outros fungos vulgares.

LESÃO EXPERIMENTAL HUMANA - Recorremos, então, a material oriundo de inoculação experimental humana.

Após ligeira escarificação, inocularam-se na perna escamas de lesão do bezerro, escamas que se mostraram ricamente parasitadas.

Decorridos 21 dias, o paciente acusava leve prurido e notavase tom avermelhado da pele inoculada; a lesão continuou a desenvolver-se e, ao fim de mais 3 dias, apresentou forma ovalada, medindo pouco mais de $21 / 2$ centímetros no seu maior eixo; era então sensìvelmente eritematosa e bastante escamosa, com escamas pequenas, sêcas, furfuráceas, desprendendo-se com facilidade.

Nas porções marginais apenas percebiam-se uma orla bastante elevada, de côr vermelha mais viva do que a área central, nelas distinguindo-se algumas e pequenas vesículas. Enfim, a lesão experimental, até seu pleno desenvolvimento, em nada se distinguia de lesão tricofítica. 
EXAME MICROSCÓPICO DAS ESCAMAS DA LESÃO EXPERIMENTAL (Potassa a $30 \%$ ). Rico entrelaçado de filamentos micelianos, longos e curtos, com e sem dicotomias, compostos de artículos grandes, quadrangulares; de permêio, viam-se filamentos, cujos artículos mostravam-se muito longos, septando muito de longe em longe o filamento (Fig. 5) (280x).

CUlturas dAs escamas DA lesão experimental - Semearamse escamas em meios glicosado, maltosado e de conservação. Só vingaram as do meio glicosado.

Foram de crescimento muito demorado: no $20^{\circ}$ dia após a semeadura, observaram-se duas culturas nascentes e de todo incaracterísticas, sob a forma de pequenas elevações esbranquiçadas. No $25 .^{\circ}$ dia cvidenciaram-se os seguintes caracteres morfológicos: 1/2 centímetro de diâmetro, superfície e côr branco-sujo irregular, com leves plicaturas que se entrecruzavam e tambem levemente penugentas, com 32 dias, a maior das colonias media pouco mais de 1 centímetro de diâmetro, a outra pouco menos. Ambas, no entanto, mostravam idênticos os demais caracteres: superfície irregular, vagamente esponjoide, mais elevada no centro, de côr branca acinzentada sobretudo na periferia; nesta a superfície é levemente pulverulenta e termina em radiações imersas no meio de cultura.

Assim mantiveram-se durante muitos dias em que foram sendo ainda observadas.

ÓRGÃOS BOTÂNICOS.

Poucos e mal diferenciados.

Ao lado de formações muito semelhantes às que se viam nas escamas - artículos grandes, quadrangulares, com abundante reserva protoplásmica e membrana evidente, existiam filamentos micelianos longos, septados de longe em longe na sua primeira porção e terminando em esboços de fusos em "batlant de cloke", uns com septações mais aproximadas, outros com elos muito distanciados.

Diagnóstico: O conjunto dos caracteres descritos permitem o diagnóstico de Tricophyton faviforme album.

\section{BIBLIOGRAFIA}

Brumpt, E. - 1927 - Précis de parasitologie. 4ème ed. Paris, Masson et Cie.

Forgeot, P. - 1935 - Traité des maladies infectieuses et contagieuses des animaux domestiques. Paris, Pierre Johanet 
Martins de Castro, A. - 1929 - Tinha dos animais domésticos em São Paulo. Arch. Inst. Biol., S. Paulo, 2: 163/78

Moraes, R. G., N. Gióvine e Moacyr G. Freitas - 1944 - Tinhas de bovinos em Minas Gerais pelo "Favotrichophyton album" (Sabouraud, 1905) NeveuLemaire, 1921. An. 2. ${ }^{\circ}$ Congresso Brasileiro Veterinária, 163/70

Sabouraud, F. - 1910 - Les maladies cryptogamiques. Paris 
L. M. Guimarães e P. M. G. Lacerda Jr., Rev. Fac. Med. Vet. S. Paulo, Vol. s, fase. 1-2 Micose em bovinos

Estampa

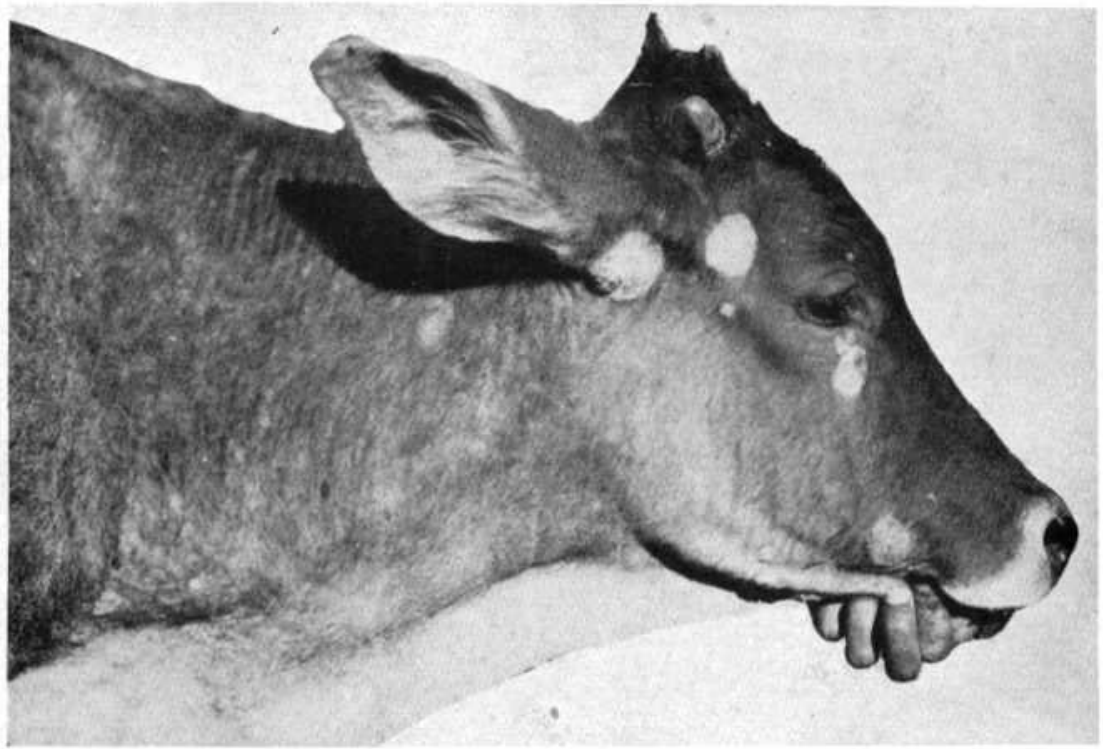

Fig. 1

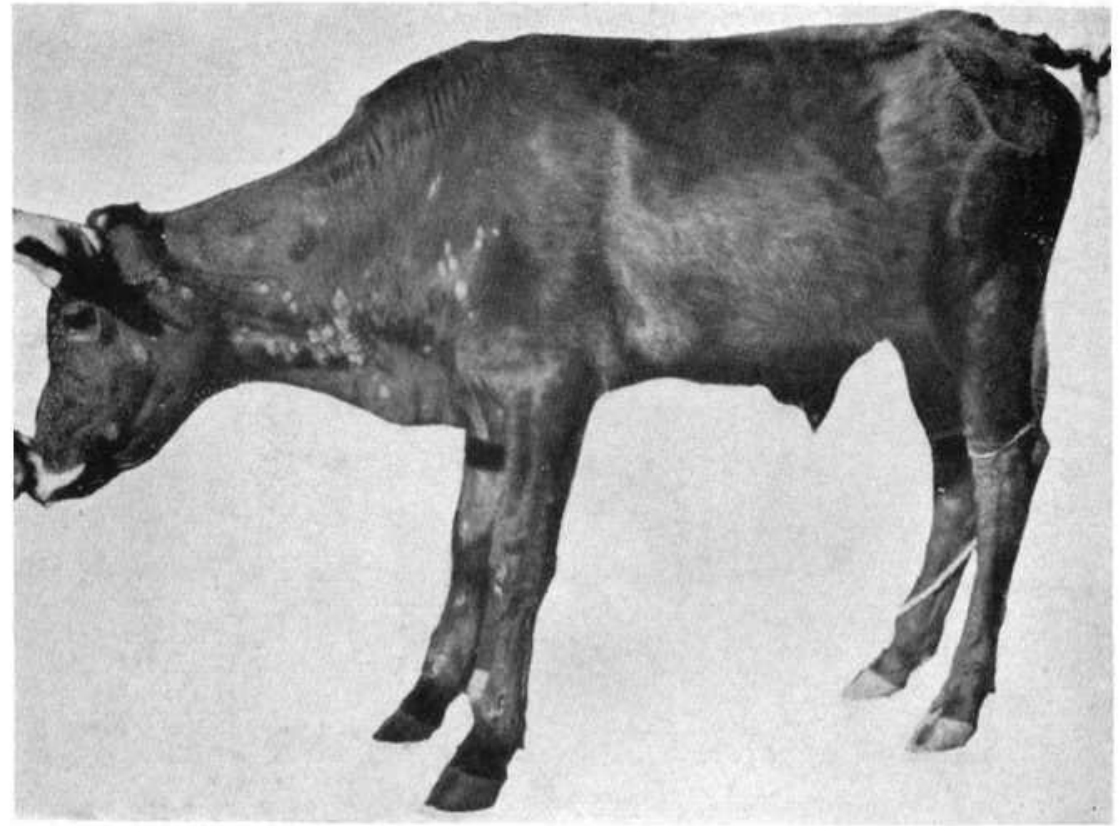

Fig. 2 
L. M. Guimaräes e P. M. G. Lacerda Jr., Rev. Fac. Med. Vet. S. Paulo, Vol. s, faso. 1-2 Micose em bovinos

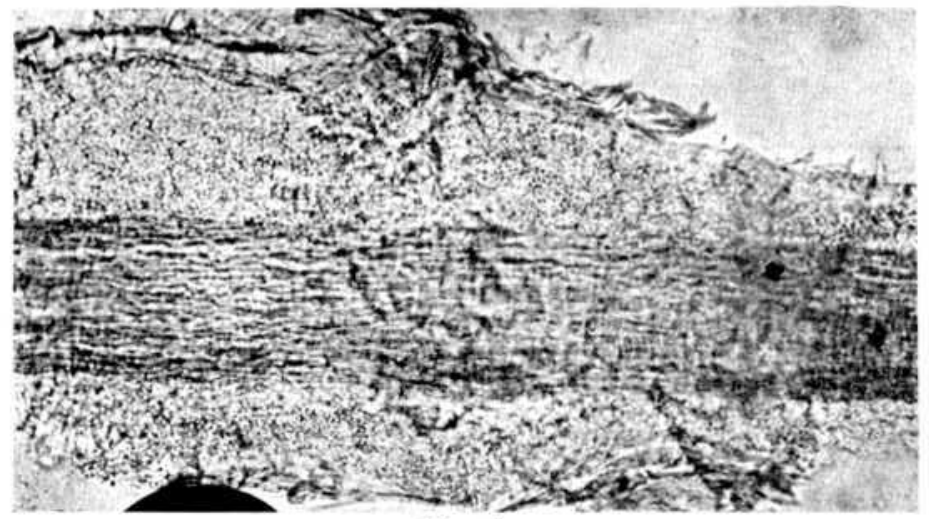

Fig. 3

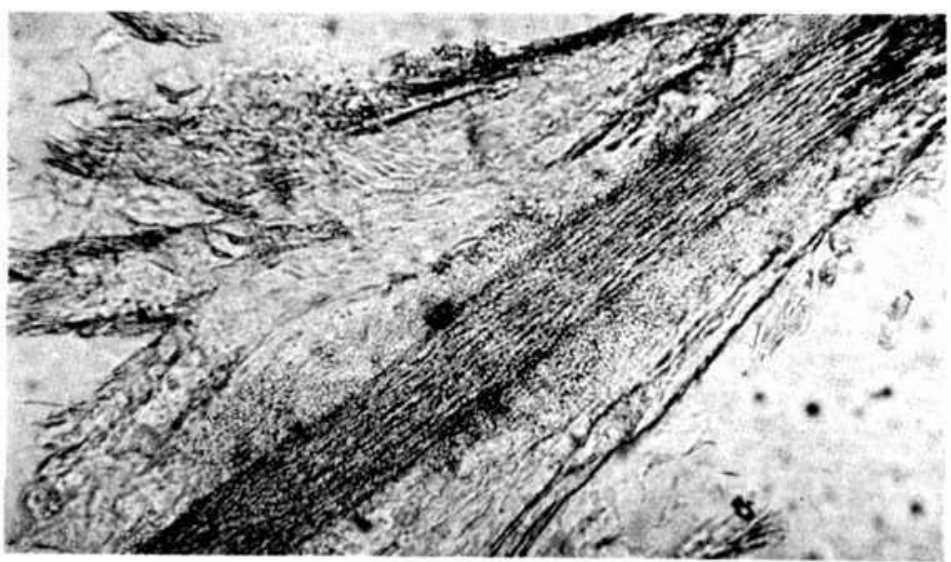

Fig. 4

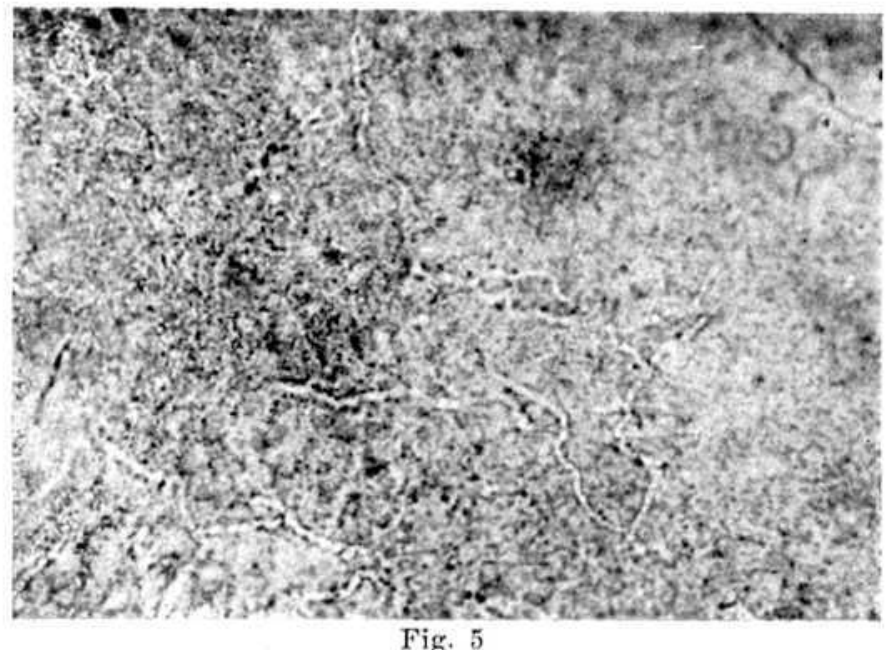

Fig. 5 